\title{
Expression and Characterization of a Novel Cold-Adapted and Stable $\beta$-Agarase Gene agaW1540 from the Deep-Sea Bacterium Shewanella sp. WPAGA9
}

\author{
Wenxin Wang ${ }^{1,+}$, Jianxin Wang ${ }^{1,+}$, Ruihua Yan ${ }^{2}$, Runying Zeng ${ }^{2}$, Yaqiang Zuo ${ }^{1}$, Dingquan Wang ${ }^{1}$ and Wu Qu ${ }^{1, *}$ \\ 1 Marine Science and Technology College, Zhejiang Ocean University, Zhoushan 316000, China; \\ Wangwenxin5688@163.com (W.W.); jxwang@zjou.edu.cn (J.W.); viento123@126.com (Y.Z.); \\ regen8616@163.com (D.W.) \\ 2 Technical Innovation Center for Utilization of Marine Biological Resources, Ministry of Natural Resources, \\ Xiamen 361000, China; 18013087015@stu.hqu.edu.cn (R.Y.); zeng@tio.org.cn (R.Z.) \\ * Correspondence: quwu2165@zjou.edu.cn \\ + Wenxin Wang and Jianxin Wang contributed equally to this work.
}

Citation: Wang, W.; Wang, J.; Yan, R.; Zeng, R.; Zuo, Y.; Wang, D.; Qu, W. Expression and Characterization of a Novel Cold-Adapted and Stable $\beta$-Agarase Gene agaW1540 from the Deep-Sea Bacterium Shewanella sp. WPAGA9. Mar. Drugs 2021, 19, 431. https://doi.org/10.3390/ md19080431

Academic Editors: Usama

Ramadan Abdelmohsen

and Mostafa Rateb

Received: 18 June 2021

Accepted: 27 July 2021

Published: 29 July 2021

Publisher's Note: MDPI stays neutral with regard to jurisdictional claims in published maps and institutional affiliations.

Copyright: (c) 2021 by the authors. Licensee MDPI, Basel, Switzerland. This article is an open access article distributed under the terms and conditions of the Creative Commons Attribution (CC BY) license (https:/ / creativecommons.org/licenses/by/ $4.0 /)$.

\begin{abstract}
The neoagaro-oligosaccharides, degraded from agarose by agarases, are important natural substances with many bioactivities. In this study, a novel agarase gene, agaW1540, from the genome of a deep-sea bacterium Shewanella sp. WPAGA9, was expressed, and the recombinant AgaW1540 (rAgaW1540) displayed the maximum activity under the optimal $\mathrm{pH}$ and temperature of 7.0 and $35^{\circ} \mathrm{C}$, respectively. $\mathrm{rAgaW} 1540$ retained $85.4 \%$ of its maximum activity at $0{ }^{\circ} \mathrm{C}$ and retained more than $92 \%$ of its maximum activity at the temperature range of $20-40{ }^{\circ} \mathrm{C}$ and the $\mathrm{pH}$ range of $4.0-9.0$, respectively, indicating its extensive working temperature and $\mathrm{pH}$ values. The activity of $\mathrm{rAgaW1540}$ was dramatically suppressed by $\mathrm{Cu}^{2+}$ and $\mathrm{Zn}^{2+}$, whereas $\mathrm{Fe}^{2+}$ displayed an intensification of enzymatic activity. The $K_{m}$ and $V_{\max }$ of rAgaW1540 for agarose degradation were $15.7 \mathrm{mg} / \mathrm{mL}$ and $23.4 \mathrm{U} / \mathrm{mg}$, respectively. rAgaW1540 retained $94.7 \%, 97.9 \%$, and $42.4 \%$ of its maximum activity after incubation at $20^{\circ} \mathrm{C}, 25^{\circ} \mathrm{C}$, and $30^{\circ} \mathrm{C}$ for $60 \mathrm{~min}$, respectively. Thin-layer chromatography and ion chromatography analyses verified that $\mathrm{rAgaW} 1540$ is an endo-acting $\beta$-agarase that degrades agarose into neoagarotetraose and neoagarohexaose as the main products. The wide variety of working conditions and stable activity at room temperatures make rAgaW1540an appropriate bio-tool for further industrial production of neoagaro-oligosaccharides.
\end{abstract}

Keywords: neoagaro-oligosaccharides; $\beta$-agarase; cold-adapted; stable; deep-sea

\section{Introduction}

Agar is the main glycan component that is segregated from the cell wall of red algae, for instance, Gracilaria sp. and Gelidium sp. [1,2]. As the major biopolymer and supporting structure in seaweed, a cocktail of agarose and agaropectin constitute the molecular structure of agar [3,4]. Agarose, as the main component of agar, possesses a linear structure that is composed of the alternant subunit of $\beta$-D-galactose and 3,6-anhydroL-galactose [5].

Agarases that depolymerize agarose into agarooligosaccharides (AOS) or neoagarooligosaccharides (NAOS) have been found in several gram-negative bacteria isolated from submarine sediments, seaweeds, marine organisms, and seawater [2]. Agarases are divided into two types, owing to the different hydrolysis modes, i.e., $\alpha$-agarase (EC 3.2.1.158), which acts on the $\alpha-1,3$ glycoside bonds and yields AOSs with 3,6-anhydro-Lgalactose at the reducing ends of products, and $\beta$-agarase (EC 3.2.1.81), which cleaves the $\beta-1,4$ glycoside bonds to generate NAOS with $\beta$-D-galactose at the reducing ends of products $[5,6]$.

Compared to $\alpha$-agarases, $\beta$-agarases have a wider distribution in nature [7]. $\beta$ agarases belong to glycoside hydrolase (GH) families, including $\mathrm{GH}$ 16, GH 39, GH 42, GH 
50, GH 86, and GH118 [2,8,9]. Neoagarobiose (NA2), neoagarotetraose (NA4), neoagarohexaose (NA6), neoagarooctaose (NA8), neoagarodecaose (NA10), and neoagarododecaose (NA12) are the usual products of $\beta$-agarases [5]. These NAOSs possess multitudinous bioactivities, such as antioxidant, antitumor, anti-obesity, anti-diabetic, anti-inflammatory, anti-cariogenic, skin whitening, and radical-scavenging activities [1,10-12], which can be widely used in the fields of food, medicine, and cosmetics.

Until now, many agarases have been thermostable but lacking in activity at low temperatures [5]. Therefore, identifying and sieving out the agarases that possess the ability of hydrolysis at low temperatures is indispensable. However, only limited agarases with cold-adaptation, such as AgaJ5, AgaJ9, and Aga21, have been identified and characterized in recent years. In detail, AgaJ5 retained $\sim 40 \%$ of the maximum enzymatic activity at $10{ }^{\circ} \mathrm{C}$ [13]. AgaJ9 maintained more than $80 \%$ of the maximum activity at $5{ }^{\circ} \mathrm{C}$ [8], and Aga21 retained as much as $85 \%$ of the maximum activity at $10{ }^{\circ} \mathrm{C}$ [14]. However, the agarases that can work at extreme temperatures, such as $0{ }^{\circ} \mathrm{C}$, are rarely reported.

Our former study demonstrated the degradation activities of a deep-sea bacterium Shewanella sp. WPAGA9 for three seaweed polysaccharides [15]. In this study, a coldadapted GH16 $\beta$-agarase, AgaW1540, from the genome of Shewanella sp. WPAGA9 had been further investigated and characterized. The results showed that the recombinant AgaW1540 (rAgaW1540) can maintain $85.4 \%$ of maximum enzymatic activity at $0{ }^{\circ} \mathrm{C}$, indicating an outstanding level of cold-adaptation. The current study provides a potential bio-tool for NAOS production at low temperatures, and an ideal model for researching the cold-adapted mechanisms of agarases.

\section{Results}

\subsection{Sequence Analysis and Purification of $r$ AgaW1540}

By the annotation against NCBI nr database, agaW1540 (GenBank accession number MZ398234) in the genome of Shewanella sp. WPAGA9 was predicted to be a putative $\beta$-agarase gene due to its maximum identity of $74.64 \%$ with the $\beta$-agarase genes from Agarivorans sp. HZ105 (GenBank accession number: HQ625023.1) and Pseudoalteromonas sp. CY24 (GenBank accession number: AY150179.3). In the phylogenetic trees constructed by the methods of maximum likelihood (Figure 1a), neighbor-joining (Figure 1b), and minimum evolution (Figure 1c), the nucleotide sequence of agaW1540 had the closest phylogenetic relationship with a $\beta$-agarase from Pseudoalteromonas sp. Q30F (GenBank accession number: MH578452.1). The annotation results from the dbCAN database assigned AgaW1540 into the GH16 family. The gene agaW1540 encoded 453 amino acids with a theoretical molecular weight of $50.96 \mathrm{kDa}$. AgaW1540 possesses an N-terminal signal peptide of 21 amino acids with a possible cleavage site between position Ala21 and Ala22. The gene agaW1540 was expressed in E. coli BL21(DE3) cells using a pEAZY ${ }^{\circledR}$-Blunt E2 expression vector (TransGen Biotech., Beijing, China). The recombinant protein was released by ultrasonication, and was purified by Ni-nitrilotriacetic acid (NTA) Sefinose ${ }^{\mathrm{TM}}$ Resin (Tiangen Biotech, Beijing, China). A single distinct band of rAgaW1540 was displayed in sodium dodecyl sulfate-polyacrylamide gel electrophoresis (SDS-PAGE) with a molecular weight of $\sim 50 \mathrm{kDa}$ (Figure 1d), which was consistent with the theoretical molecular weight. 
a

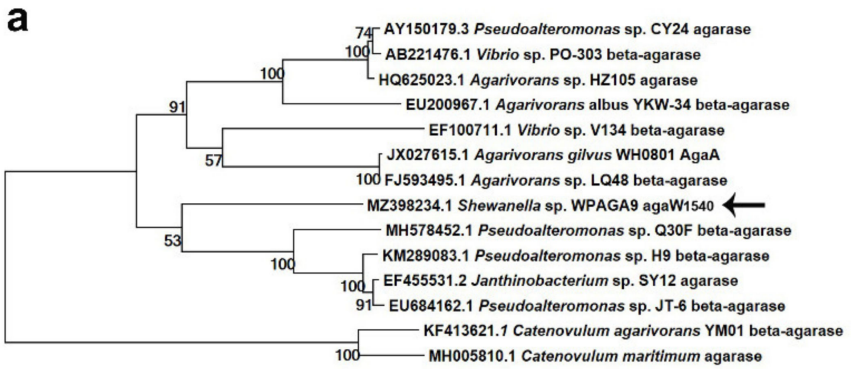

0.1

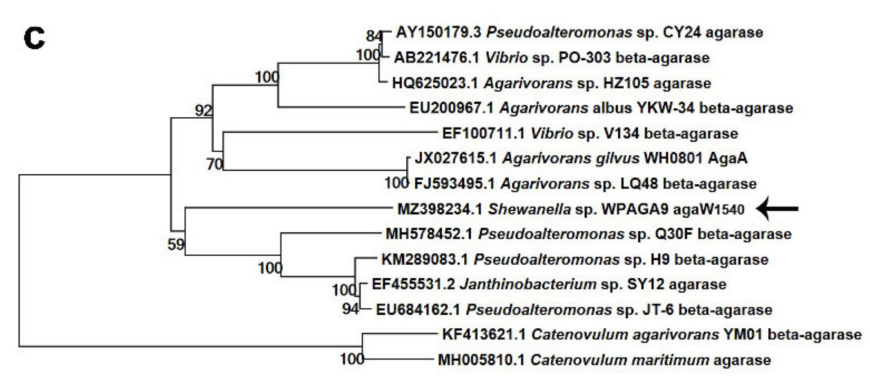

0.1
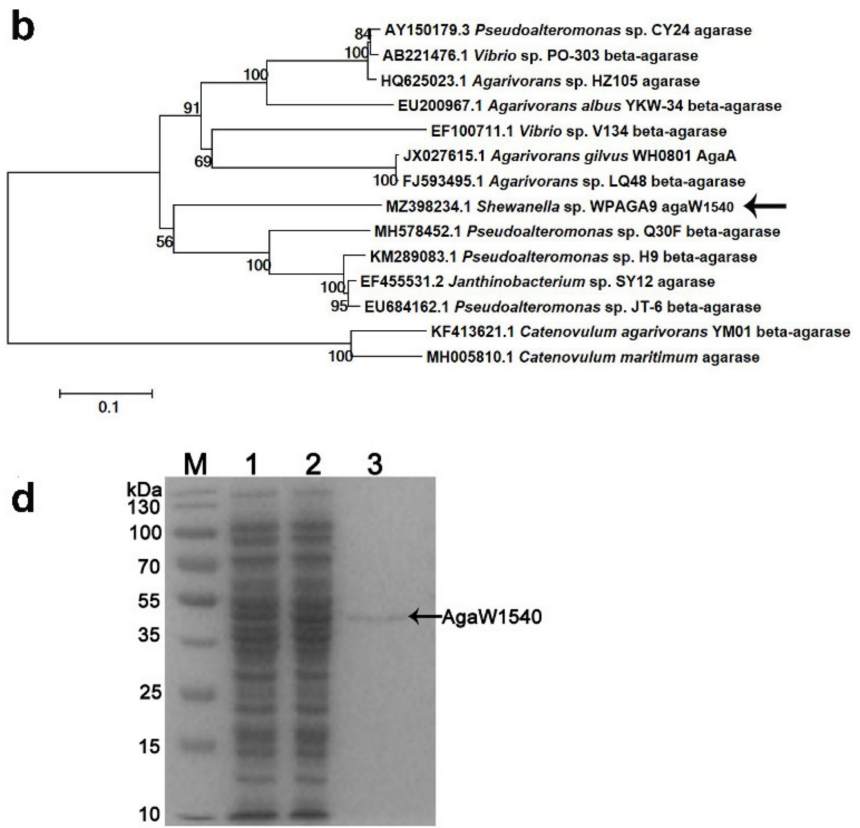

Figure 1. Phylogenetic analysis of the nucleotide sequence of agaW1540 based on the methods of maximum likelihood (a), neighbor-joining (b), and minimum evolution (c) and SDS-PAGE result of purified rAgaW1540 (d). The phylogenetic trees were generated by using Mega 5.2 software. Bootstrap values of 1000 replications are displayed at branching points. The scale plate denoting ten nucleotide substitutions per 100 nucleotides is shown at the bottom. The gene of agaW1540 is indicated in bold with arrows. (d) SDS-PAGE of the purified rAgaW1540. Lane M, protein maker; Lane 1, cell lysate before induction; Lane 2, cell lysate after induction; Lane 3, purified rAgaW1540. As the figure displayed, the arrow expounds the position of the rAgaW1540 band.

\subsection{Biochemical Characterization and Enzymatic Features of rAgaW1540}

The optimum $\mathrm{pH}$ of rAgaW1540 was 7.0. Meanwhile, rAga1540 exhibited the maximum activity at an extensive $\mathrm{pH}$ coverage, and maintained $98.2 \%, 93.6 \%$, and $98.4 \%$ of the maximum activity at $\mathrm{pH} 4.0,5.0$, and 6.0, respectively (Figure 2a). The optimum temperature of rAgaW1540 was $35{ }^{\circ} \mathrm{C}$ (Figure 2b). rAgaW1540 retained 92.8\%, 98.9\%, and 93.1\% of its maximum activity at 20,30, and $40{ }^{\circ} \mathrm{C}$, respectively. Furthermore, rAgaW1540 maintained $85.4 \%$ of its maximum activity at $0^{\circ} \mathrm{C}$, elucidating that rAgaW1540 is a cold-adapted agarase. 

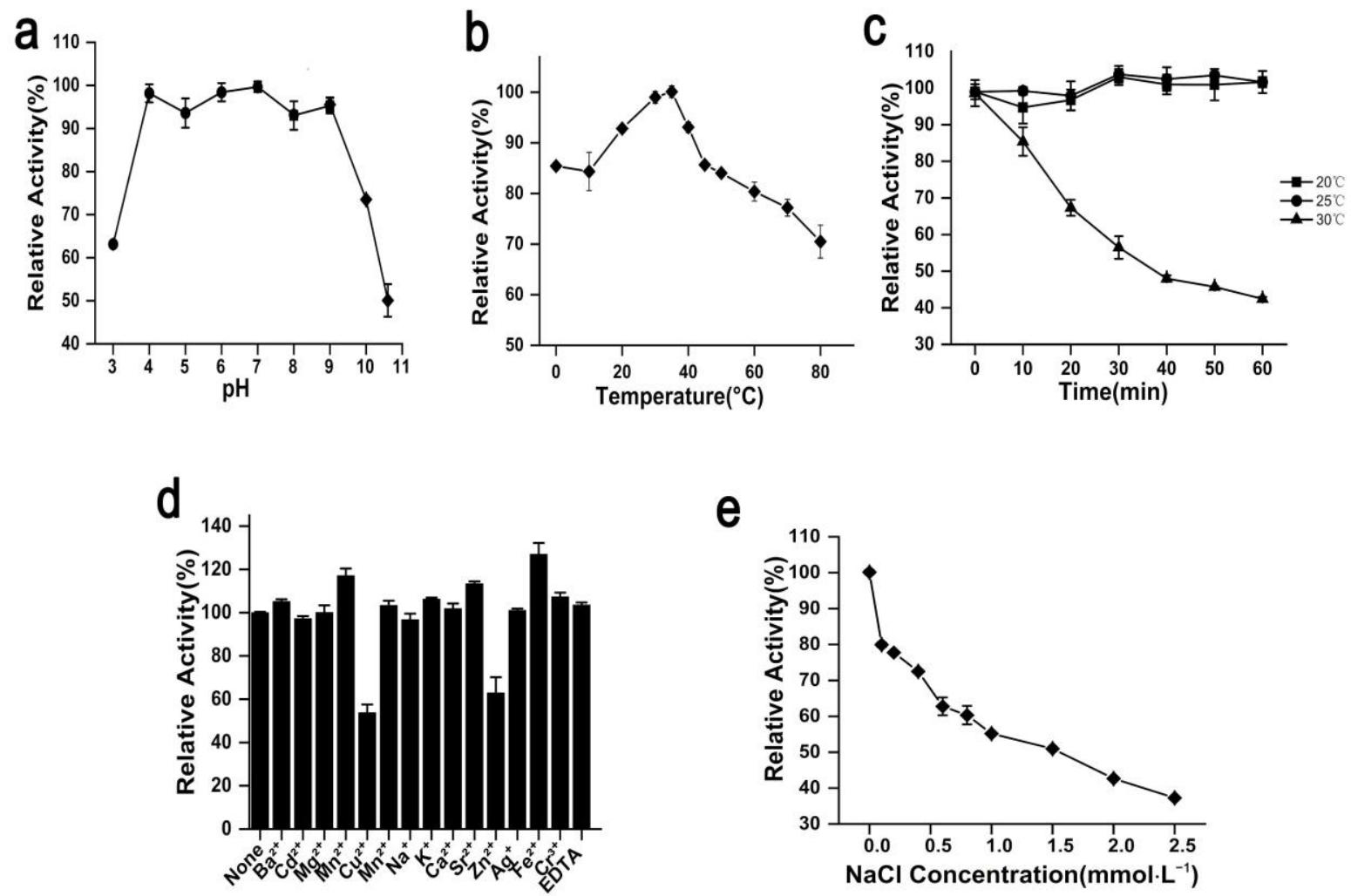

Figure 2. Biochemical properties of rAgaW1540. (a) $\mathrm{pH}$ effects on the enzymatic activity of rAgaW1540 with the range of 3.0-10.6. (b) The temperature effects on enzymatic activity with a temperature range of 0 to $80{ }^{\circ} \mathrm{C}$. (c) The thermal stability of rAgaW1540. (d) The effect of chemical reagents on the enzymatic activity. (e) The effect of $\mathrm{NaCl}$ on enzymatic activity with a concentration range of $0-2.5 \mathrm{~mol} \cdot \mathrm{L}^{-1}$. All the plot values displayed above are relative numbers of the maximum activity of rAgaW1540 (presented as 100\%) and repeat three times that are denoted with standard deviation (SD).

\subsection{Stability of rAgaW1540 against Temperatures and Other Potential Inhibitors}

rAgaW1540 showed stability at ambient temperatures. The results of thermal stability experiments elaborated that rAgaW1540 maintained $94.7 \%$ and $97.9 \%$ of its maximum activity after the pre-incubation at $20^{\circ} \mathrm{C}$ and $25^{\circ} \mathrm{C}$ for $1 \mathrm{~h}$, respectively (Figure $2 \mathrm{c}$ ). However, the activity of rAgaW1540 was mostly lost after incubation at $30^{\circ} \mathrm{C}$. Among the metal ions additives, $\mathrm{Cu}^{2+}$ and $\mathrm{Zn}^{2+}$ had negative effects on rAgaW1540; meanwhile, $\mathrm{Ba}^{2+}, \mathrm{Mn}^{2+}$, $\mathrm{Ni}^{2+}, \mathrm{K}^{+}, \mathrm{Ga}^{2+}, \mathrm{Sr}^{2+}, \mathrm{Ag}^{+}, \mathrm{Cr}^{2+}$, and EDTA slightly promoted the enzymatic activity of eAgaW1540. $\mathrm{Fe}^{2+}$ exhibited a promotion that increased the relative activity of rAgaW1540 up to $126.99 \%$ (Figure $2 \mathrm{~d}$ ). $\mathrm{NaCl}$ exhibited a suppression on the enzymatic activity of rAgaW1540 (Figure 2e), and the $V_{\max }$ and $K_{m}$ of rAgaW1540 for agarose were $23.4 \mathrm{U} / \mathrm{mg}$ and $15.7 \mathrm{mg} / \mathrm{mL}$, respectively.

\subsection{The Degradation Products of rAgaW1540 for Agarose}

Based on the results of thin-layer chromatography (TLC), agarose was firstly degraded into NA12, NA8, NA6, and NA4 after degradation for $10 \mathrm{~min}$, which suggested rAgaW1540 was an endo-type agarase. Subsequently, NA12 and NA8 were further degraded into NA4 and NA6. The main products of rAgaW1540 were NA4 and NA6 after degradation for $24 \mathrm{~h}$ (Figure 3a). To further confirm the hydrolysates of rAgaW1540, the products that were degraded for $48 \mathrm{~h}$ were identified by ion chromatography (IC; Figure $3 \mathrm{~b}$ ). The results of the IC analysis revealed that the agarolytic products of $\mathrm{rAgaW} 1540$ had similar retention times with NA2, NA4, NA6, and NA8. Furthermore, NA4 and NA6 had the largest proportions among these oligosaccharides, indicating that NA4 and NA6 were the main products of rAgaW1540. 


\section{a}

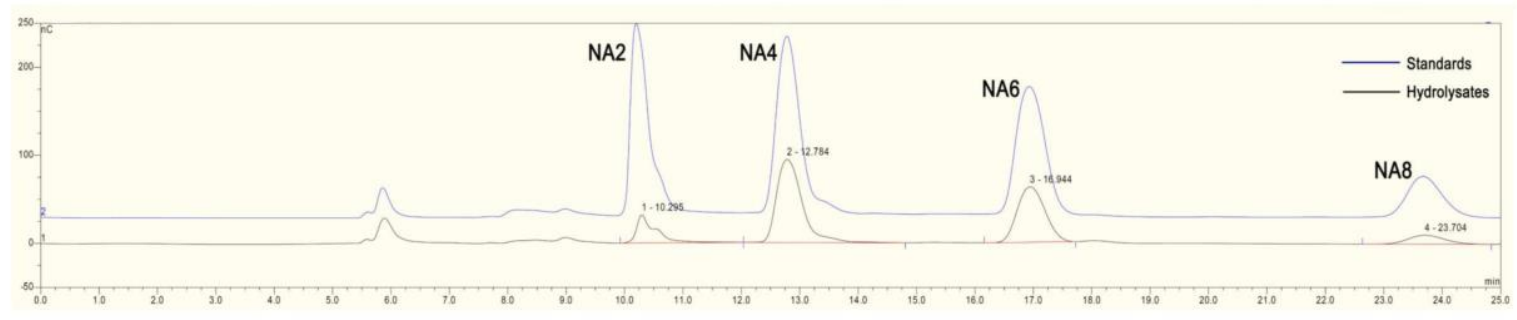

b

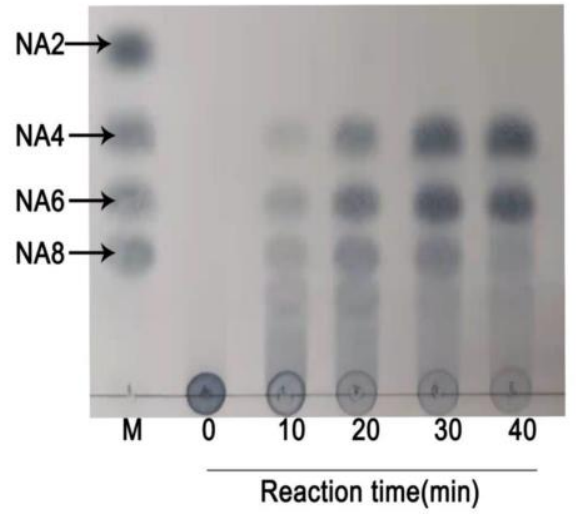

Figure 3. IC chromatogram (a) and TLC analysis (b) of the hydrolysates of AgaW1540. NA2, neoagarobiose; NA4, neoagarotetraose; NA6, neoagarohexaose; NA8, Neoagarooctaose.

\subsection{Fermentation Optimization of rAgaW1540 Production}

Leakage expression was observed because the activity of rAgaW1540 was detected without the induction of isopropyl- $\beta$-D-thiogalactopyranoside (IPTG; Figure 4a). The production of rAgaW1540 peaked at an IPTG concentration of $0.1 \mathrm{mmol} \cdot \mathrm{L}^{-1}$ (Figure 4a). High IPTG concentrations could inhibit the production of soluble rAgaW1540 (Figure 4a). The optimum time for inducing the production of rAgaW1540 by IPTG was $16 \mathrm{~h}$ (Figure $4 \mathrm{~b}$ ). The production of rAgaW1540 maximized at the induction temperatures of $20-24{ }^{\circ} \mathrm{C}$ (Figure $4 \mathrm{c}$ ).
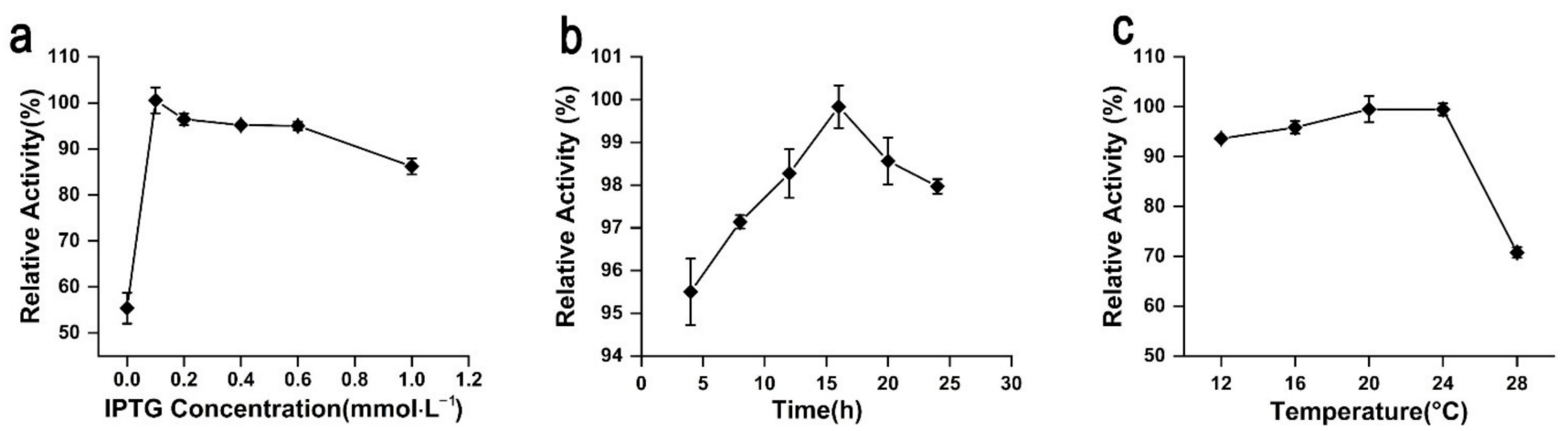

Figure 4. The effects of IPTG concentrations (a), reaction time (b), and induction temperatures (c) on the production of rAgaW1540.

\section{Discussion}

Herein, we overexpressed a novel $\beta$-agarase gene agaW1540 from the genome of a deep-sea bacterium Shewanella sp. WPAGA9. The newfound enzyme that belonged to the GH16 family was biochemically characterized as an endo-type $\beta$-agarase with the optimal bioactivity at $\mathrm{pH} 7.0$ and $35^{\circ} \mathrm{C}$ with the main products of NA4 and NA6. The stability of agarase exerts an important influence on the application of its industrial production [16]. The results indicated that $\mathrm{rAgaW} 1540$ was very stable against pre-incubation at ambient 
temperatures of $20^{\circ} \mathrm{C}$ and $25^{\circ} \mathrm{C}$. Until now, most agarases have been difficult to stabilize at room temperature [17], which extremely impeded their industrial utilizations. To conserve their bioactivity, it has been necessary to decrease the storage temperature of the enzymes during the industrial production process, which can cause a waste of energy. Therefore, rAgaW1540, with its outstanding room-temperature stability, could become a less costly agarase alternative.

rAgaW1540 adapted to a broad $\mathrm{pH}$ range of 4.0-9.0, as it maintained more than $93 \%$ of the maximum activity at these $\mathrm{pH}$ values, which was much higher than most of the $\mathrm{pH}$-stable agarases that originated from different marine bacteria [15,17,18]. For instance, Aga3027 has been reported to maintain more than $85 \%$ of its enzymatic activity at pH 7.0-9.0 [18]. AgaB is stable at $\mathrm{pH} 6.5-8.5$, as more than $80 \%$ of the enzymatic activity was retained [16]. Aga862 retains $80 \%$ of its relative activity at $\mathrm{pH} 3.0-10.0$ [19]. The wide $\mathrm{pH}$ ranges facilitate the adaptability of rAgaW1540 to $\mathrm{pH}$ change during the reaction process. Additionally, the high activity of rAgaW1540 at alkaline pHs could effectively decrease the expenditure of neutralizing alkali in the course of extracting NAOS from the biotransformation of agar, which is a more friendly method of NAOS production [18].

rAgaW1540 had a good cold-adaptation. This agarase maintained $85.42 \%$ of its maximum activity at $0{ }^{\circ} \mathrm{C}$. Four $\beta$-agarases, including three $\beta$-agarases from Gayadomonas joobiniege $\mathrm{G} 7$ and one from Pseudoalteromonas sp. NJ21, have been reported to possess cold-adaptation. These agarases were variously sorted into the GH39, GH42, and GH86 families. In detail, AgaJ5 possesses a prominent cold tolerance, as it retained enzymatic activity of $40 \%$ at $10{ }^{\circ} \mathrm{C}$ [13]; AgaJ9 sustained 89\% of agarase activity at $10{ }^{\circ} \mathrm{C}$ [8]; AgaJ10 showed 50\% of enzymatic activity at $10{ }^{\circ} \mathrm{C}$ [9]; whereas Aga21 retained $85 \%$ of enzymatic activity at $10{ }^{\circ} \mathrm{C}$ [14]. Nevertheless, the agarases that can work at $0{ }^{\circ} \mathrm{C}$ are rarely reported. Our study provides an insight into a novelty agarase with high activity at $0^{\circ} \mathrm{C}$. The cold-adapted rAgaW1540 could maintain efficient activity at low temperatures in extreme conditions, such as deep-sea environments. This property enables the deep-sea strain WPAGA9 to rapidly degrade and utilize the carbon source, which is key for its growth and element cycling in a deep-sea environment. Notably, cold-adaptation is not a common characteristic among the existing agarases, even for the agarases isolated from deep-sea bacteria [5,20]. For example, agarase HZ2 [21], AgaP4383, and Aga4436 [6] from deep-sea bacteria cannot maintain their activities at temperatures lower than $5^{\circ} \mathrm{C}$. Therefore, this study also provides an ideal but rare structure model for future research on the cold-adapted mechanisms of proteins.

Neoagaro-oligosaccharides, the products hydrolyzed by agarases, possess multifold physiological bioactivities, including prebiotics, antioxidant, anti-inflammatory, antiobesity, and skin moisturizing effects $[10,11,22-24]$. In this study, NA4 and NA6 were the main products of agarose degradation by rAgaW1540. To date, NA4 has been found to attenuate the inflammatory responses [25]. Additionally, a recent report demonstrated that NA4 can selectively modulate gut microbial community composition and regulate multiple intestine metabolites to alleviate inflammation [26]. NA6 was reported to possess a potential antitumor immunity and act as a cell modulator towards melanoma, and afterwards was verified to have an antivirus inborn immunity against norovirus [12,27]. Owing to these properties, in this study, rAgaW1540 can be further applied in food, medicine, and cosmetic industries.

In summary, this study explores an agarase rAgaW1540 from a deep-sea bacterium. The wide $\mathrm{pH}$ and temperature working range make rAgaW1540 stable and adaptable to environmental variation during the reaction process. rAgaW1540 is convenient for storage and transportation due to its strong stability at room temperatures. Notably, rAgaW1540, with its cold-adaptation, could possibly facilitate the carbon cycling in the low temperatures of deep-sea environments and provide a potentially valuable model for researching the mechanisms of protein cold tolerance. 


\section{Materials and Methods}

\subsection{Sequence Analysis and Cloning of agaW1540}

The nucleotide sequence of agaW1540 had been deposited in the GenBank database under the accession number MZ398234. The sequence of agaW1540 was annotated against NCBI nr (ftp:/ / ftp.ncbi.nlm.nih.gov/blast/db, accessed on 7 July 2020) and dbCAN ( http:/ / csbl.bmb.uga.edu/dbCAN/, accessed on 7 July 2020) databases. Based on the nucleotide sequences, the agarase genes were aligned by using ClustalW and the phylogenetic analysis was performed by the methods of neighbor-joining, maximum likelihood, and minimum evolution in MEGA 5.2 software (https:/ /www.megasoftware.net/, accessed on 19 July 2021) with a bootstrap value of 1000 . The prediction of signal peptide was performed by using SignalP-5.0 (http://www.cbs.dtu.dk/services/SignalP/, accessed on 7 July 2020). Shewanella sp. WPAGA9 was cultured in marine broth 2216E (5.0 g peptone, 1.0 g yeast extract, $0.01 \mathrm{~g}$ iron phosphate, and $1 \mathrm{~L}$ seawater; $\mathrm{pH} 7.4$ ) at $30{ }^{\circ} \mathrm{C}$ for $12 \mathrm{~h}$. The genomic DNA of Shewanella sp. WPAGA9 (GenBank accession number: CP062058) was extracted by using a TIANamp Bacteria DNA Kit (Tiangen Biotech., Beijing, China). The gene agaW1540 was amplified through PCR with a forward primer (5'-AAACCTAGTATGAATGTTATCTATGCTACTAC-3') and a reverse primer (5'-CTCTACTTTAAATTGTTGATTGGTTCCG-3'). PCR was conducted using a C1000 ${ }^{\mathrm{TM}}$ Thermal Cycler (Bio-Rad CO., Ltd., Hercules, CA, USA) and the PCR condition was as follows: 3 min at $95^{\circ} \mathrm{C} ; 25$ cycles of $95^{\circ} \mathrm{C}$ for $25 \mathrm{~s}, 55^{\circ} \mathrm{C}$ for $25 \mathrm{~s}, 72{ }^{\circ} \mathrm{C}$ for $1 \mathrm{~min} / \mathrm{kb}$; and extension at $72{ }^{\circ} \mathrm{C}$ for $6 \mathrm{~min}$. The PCR products were purified by Universal DNA Purification Kit (Tiangen Biotech., Beijing, China) and then were ligated with pEAZY ${ }^{\circledR}$-Blunt E2 expression vector (TransGen Biotech., Beijing, China). The recombinant vector harboring agaW1540 gene was transformed into E. coli BL21(DE3) pLysS cells.

\subsection{Expression and Purification of $\mathrm{r}$ AgaW1540}

The E. coli BL21(DE3) pLysS cells harboring the recombinant vector were cultured at $37^{\circ} \mathrm{C}$ in LB broth (5.0 g yeast extracts, $10.0 \mathrm{~g}$ peptone, $10.0 \mathrm{~g} \mathrm{NaCl}$, and $1 \mathrm{~L}$ deionized water) including $100 \mu \mathrm{g} / \mathrm{mL}$ ampicillin, and the culture broth was induced by adding $0.1 \mathrm{mM}$ IPTG at $16{ }^{\circ} \mathrm{C}$ until the $\mathrm{OD}_{600 \mathrm{~nm}}$ reached $0.6-0.8$. The cells were collected by centrifugation at $10,000 \mathrm{rpm}$ for $10 \mathrm{~min}$ at $4{ }^{\circ} \mathrm{C}$, and then were subsequently resuspended in a Tris- $\mathrm{HCl}$ buffer (10 mM; pH 7.4). The resuspended cells were fractured using a sonicator (Scientz, Ningbo, China) at a rate of $3 \mathrm{~s} / 2 \mathrm{~s}$ impulse frequency for $20 \mathrm{~min}$ in ice. The Ni-nitrilotriacetic acid (NTA) Sefinose ${ }^{\mathrm{TM}}$ Resin (Tiangen Biotech, Beijing, China) was used to further purify rAgaW1540 with $6 \times$ His-tagged from the crude enzyme solution. The molecular weight and purity of rAgaW1540 were subsequently estimated by SDS-PAGE and Coomassie brilliant blue staining.

\subsection{Characterization of Enzymatic Properties}

The agarase activity $(\mathrm{U})$ was defined as the amount of the enzyme that released $1 \mu \mathrm{mol}$ of reducing sugars per minute under certain conditions. In detail, $10 \mu \mathrm{L}$ enzyme solution was mixed with $240 \mu \mathrm{L}$ agarose $(0.4 \% ; w / v)$ with different pHs including $3.0-8.0(50 \mathrm{mM}$ sodium citrate-dibasic sodium phosphate), 8.0-9.0 (50 mM Tris- $\mathrm{HCl}$ ), and 9.0-10.6 (50 mM glycine- $\mathrm{NaOH}$ ), and the mixture was incubated at the temperatures of $0,10,20,30,35,40$, $45,50,60,70$, and $80^{\circ} \mathrm{C}$ for $10 \mathrm{~min}$, respectively. Then, $750 \mu \mathrm{L}$ 3,5-dinitrosalicylic acid (DNS) solution was added, and the resulting sugar was measured by the DNS method [28]. To determine the stability against $\mathrm{pH}$, rAgaW1540 was pre-incubated in the above-mentioned $\mathrm{pH}$ buffers at $25^{\circ} \mathrm{C}$ for $60 \mathrm{~min}$, and then the residual activity was determined. To determine the thermostability, $\mathrm{rAgaW} 1540$ was pre-incubated at 20,25 , and $30^{\circ} \mathrm{C}$ for $60 \mathrm{~min}$, and then the residual activity was determined. The effects of metal ions and metal chelators were measured by determining the enzymatic activity of rAgaW1540 in the solution containing $\mathrm{Ba}^{2+}, \mathrm{Cd}^{2+}, \mathrm{Mg}^{2+}, \mathrm{Mn}^{2+}, \mathrm{Cu}^{2+}, \mathrm{Ni}^{2+}, \mathrm{Na}^{+}, \mathrm{K}^{+}, \mathrm{Ga}^{2+}, \mathrm{Sr}^{2+}, \mathrm{Zn}^{2+}, \mathrm{Ag}^{+}, \mathrm{Fe}^{2+}, \mathrm{Cr}^{2+}$, and EDTA at a final concentration of $10 \mathrm{mM}$. The effect of $\mathrm{NaCl}$ concentrations on rAgaW1540 activity was measured by determining the activity at the $\mathrm{NaCl}$ concentrations of $0-2.5 \mathrm{~mol} \cdot \mathrm{L}^{-1}$. 
The kinetic parameters of rAgaW1540 were measured by determining the activity with the agarose at final concentrations of $0.1-0.6 \mathrm{mg} / \mathrm{mL}$ without any metal additive, and the $K_{m}$ and $V_{\max }$ values were subsequently calculated by the Lineweaver-Burk plot. All determinations were repeated three times.

\subsection{Identification of the Hydrolysates of $r$ AgaW1540}

TLC analysis was conducted to investigate the hydrolysis modes and products of rAgaW1540 in 0, 10, 20, 30, and $40 \mathrm{~min}$. The agarolytic reaction of rAgaW1540 were conducted in a $50 \mathrm{mM}$ Tris- $\mathrm{HCl}$ buffer $(\mathrm{pH} 7.0)$ with $0.1 \%$ agarose $(w / v)$ at $25{ }^{\circ} \mathrm{C}$. The products were developed on a silica gel 60 plate (Merck, Darmstadt, Germany) with the developing solvent containing n-butanol, acetic acid, and water $(2: 1: 1 ; v / v / v)$. The products on the plates were visualized by heating with $20 \% \mathrm{H}_{2} \mathrm{SO}_{4}$ at $130{ }^{\circ} \mathrm{C}$ for $10 \mathrm{~min}$. To further identify the degradation products, the hydrolysates of rAgaW1540 were analyzed by IC. A Dionex CarboPac PA-100 column $(4 \times 250 \mathrm{~mm})$ was used to separate the oligosaccharides. The mobile phases were $100 \mathrm{mmol} / \mathrm{L} \mathrm{NaOH}$ and $150 \mathrm{mmol} / \mathrm{L} \mathrm{NaAc}$, and the flow rate was $0.25 \mathrm{~mL} / \mathrm{min}$. The injection volume was $25 \mu \mathrm{L}$. The commercial neoagaro-oligosaccharides, including NA2, NA4, NA6, and NA8, were used as standards for TLC and IC analyses.

\subsection{Fermentation Optimization of rAgaW1540 Production in E. coli Cells}

To enhance product yields, fermentation optimization was performed to improve the expression condition of rAgaW1540 in E. coli cells. First, the IPTG concentration was optimized. Different concentrations $(0,0.1,0.2,0.4,0.6$, and $1.0 \mathrm{mM})$ of IPTG solution were added into the fermentation broth to reduce the recombinant proteins. Then, the agarose activity was measured by the method in section "Characterization of enzymatic properties". The induction time was future optimized by determining the agarase activity in the fermentation broth after 4, 8, 12, 16, 20, and $24 \mathrm{~h}$ inductions by IPTG. The induction temperatures, including $12,16,20,24$, and $28 \mathrm{~h}$, were also optimized to increase the production of rAgaW1540.

Author Contributions: Conceptualization, W.Q. and R.Z.; methodology, W.W., R.Y. and D.W.; software, J.W.; validation, W.W., R.Y., and J.W.; formal analysis, W.W., J.W. and R.Y.; investigation, W.W., J.W. and R.Y.; resources, W.Q. and J.W.; data curation, W.Q.; writing—original draft preparation, W.W. and J.W.; writing —review and editing, W.Q.; visualization, W.W., R.Y. and Y.Z.; supervision, W.Q.; project administration, W.Q.; funding acquisition, W.Q. and J.W. All authors have read and agreed to the published version of the manuscript.

Funding: This research was supported by grants from Science and Technology Program of Zhoushan (No. 2021C21009), National Key R\&D Program of China (No. 2019YFD0901305), and Technology Innovation Center for Exploitation of Marine Biological Resources, MNR (No. TICMBR202102).

Institutional Review Board Statement: Not applicable.

Informed Consent Statement: Not applicable.

Data Availability Statement: The nucleotide sequence of the gene agaW1540 had been deposited in the GenBank database under the accession number MZ398234.

Conflicts of Interest: The authors state that there is no conflict of interest.

\section{References}

1. Hong, S.J.; Lee, J.H.; Kim, E.J.; Yang, H.J.; Park, J.S.; Hong, S.K. Toxicological evaluation of neoagarooligosaccharides prepared by enzymatic hydrolysis of agar. Regul. Toxicol. Pharmacol. 2017, 90, 9-21. [CrossRef]

2. Fu, X.T.; Kim, S.M. Agarase: Review of major sources, categories, purification method, enzyme characteristics and applications. Mar. Drugs 2010, 8, 200-218. [CrossRef] [PubMed]

3. Mostafavi, F.S.; Zaeim, D. Agar-based edible films for food packaging applications-A review. Int. J. Biol. Macromol. 2020, 159, 1165-1176. [CrossRef]

4. Lee, W.K.; Lim, Y.Y.; Leow, A.T.; Namasivayam, P.; Ong Abdullah, J.; Ho, C.L. Biosynthesis of agar in red seaweeds: A review. Carbohydr. Polym. 2017, 164, 23-30. [CrossRef] [PubMed] 
5. Park, S.H.; Lee, C.R.; Hong, S.K. Implications of agar and agarase in industrial applications of sustainable marine biomass. Appl. Microbiol. Biotechnol. 2020, 104, 2815-2832. [CrossRef] [PubMed]

6. Chen, X.L.; Hou, Y.P.; Jin, M.; Zeng, R.Y.; Lin, H.T. Expression and Characterization of a Novel Thermostable and pH-Stable $\beta$-Agarase from Deep-Sea Bacterium Flammeovirga Sp. OC4. J. Agric. Food Chem. 2016, 64, 7251-7258. [CrossRef]

7. Sun, H.; Gao, L.; Xue, C.; Mao, X. Marine-polysaccharide degrading enzymes: Status and prospects. Compr. Rev. Food Sci. Food Saf. 2020, 19, 2767-2796. [CrossRef] [PubMed]

8. Jung, S.; Lee, C.R.; Chi, W.J.; Bae, C.H.; Hong, S.K. Biochemical characterization of a novel cold-adapted GH39 $\beta$-agarase, AgaJ9, from an agar-degrading marine bacterium Gayadomonas joobiniege G7. Appl. Microbiol. Biotechnol. 2017, 101, 1965-1974. [CrossRef]

9. Choi, U.; Jung, S.; Hong, S.K.; Lee, C.R. Characterization of a Novel Neoagarobiose-Producing GH42 $\beta$-Agarase, AgaJ10, from Gayadomonas joobiniege G7. Appl. Biochem. Biotechnol. 2019, 189, 1-12. [CrossRef]

10. Yu, S.; Yun, E.J.; Kim, D.H.; Park, S.Y.; Kim, K.H. Anticariogenic Activity of Agarobiose and Agarooligosaccharides Derived from Red Macroalgae. J. Agric. Food Chem. 2019, 67, 7297-7303. [CrossRef]

11. Hong, S.J.; Lee, J.H.; Kim, E.J.; Yang, H.J.; Park, J.S.; Hong, S.K. Anti-Obesity and Anti-Diabetic Effect of Neoagarooligosaccharides on High-Fat Diet-Induced Obesity in Mice. Mar. Drugs 2017, 15, 90. [CrossRef] [PubMed]

12. Lee, M.H.; Jang, J.H.; Yoon, G.Y.; Lee, S.J.; Lee, M.G.; Kang, T.H.; Han, H.D.; Kim, H.S.; Choi, W.S.; Park, W.S.; et al. Neoagarohexaose-mediated activation of dendritic cells via Toll-like receptor 4 leads to stimulation of natural killer cells and enhancement of antitumor immunity. BMB Rep. 2017, 50, 263-268. [CrossRef] [PubMed]

13. Lee, Y.R.; Jung, S.; Chi, W.J.; Bae, C.H.; Jeong, B.C.; Hong, S.K.; Lee, C.R. Biochemical Characterization of a Novel GH86 $\beta$-Agarase Producing Neoagarohexaose from Gayadomonas joobiniege G7. J. Microbiol. Biotechnol. 2018, 28, 284-292. [CrossRef] [PubMed]

14. Li, J.; Hu, Q.; Li, Y.; Xu, Y. Purification and characterization of cold-adapted beta-agarase from an Antarctic psychrophilic strain Braz. J. Microbiol. 2015, 46, 683-690. [CrossRef] [PubMed]

15. Wang, D.; Wang, J.; Zeng, R.; Wu, J.; Michael, S.V.; Qu, W. The degradation activities for three seaweed polysaccharides of Shewanella sp. WPAGA9 isolated from deep-sea sediments. J. Basic Microbiol. 2021, 61, 406-418. [CrossRef] [PubMed]

16. Dong, Q.; Ruan, L.; Shi, H. A $\beta$-agarase with high $\mathrm{pH}$ stability from Flammeovirga sp. SJP92. Carbohydr. Res. 2016, 432, 1-8. [CrossRef] [PubMed]

17. Jahromi, S.T.; Barzkar, N. Future direction in marine bacterial agarases for industrial applications. Appl. Microbiol. Biotechnol. 2018, 102, 6847-6863. [CrossRef] [PubMed]

18. Chen, X.; Lin, H.; Jin, M.; Zeng, R.; Lin, M. Characterization of a novel alkaline $\beta$-agarase and its hydrolysates of agar. Food Chem. 2019, 295, 311-319. [CrossRef] [PubMed]

19. Cui, X.; Jiang, Y.; Chang, L.; Meng, L.; Yu, J.; Wang, C.; Jiang, X. Heterologous expression of an agarase gene in Bacillus subtilis, and characterization of the agarase. Int. J. Biol. Macromol. 2018, 120, 657-664. [CrossRef] [PubMed]

20. Yun, E.J.; Yu, S.; Kim, K.H. Current knowledge on agarolytic enzymes and the industrial potential of agar-derived sugars. Appl. Microbiol. Biotechnol. 2017, 101, 5581-5589. [CrossRef]

21. Lin, B.; Lu, G.; Zheng, Y.; Xie, W.; Li, S.; Hu, Z. Gene cloning, expression and characterization of a neoagarotetraose-producing $\beta$-agarase from the marine bacterium Agarivorans sp. HZ105. World J. Microbiol. Biotechnol. 2012, 28, 1691-1697. [CrossRef] [PubMed]

22. Gurpilhares, D.B.; Cinelli, L.P.; Simas, N.K.; Pessoa, A., Jr.; Sette, L.D. Marine prebiotics: Polysaccharides and oligosaccharides obtained by using microbial enzymes. Food Chem. 2019, 280, 175-186. [CrossRef] [PubMed]

23. Cheong, K.L.; Qiu, H.M.; Du, H.; Liu, Y.; Khan, B.M. Oligosaccharides Derived from Red Seaweed: Production, Properties, and Potential Health and Cosmetic Applications. Molecules 2018, 23, 2451. [CrossRef]

24. Kim, J.H.; Yun, E.J.; Yu, S.; Kim, K.H.; Kang, N.J. Different Levels of Skin Whitening Activity among 3,6-Anhydro-l-galactose, Agarooligosaccharides, and Neoagarooligosaccharides. Mar. Drugs 2017, 15, 321. [CrossRef]

25. Wang, W.; Liu, P.; Hao, C.; Wu, L.; Wan, W.; Mao, X. Neoagaro-oligosaccharide monomers inhibit inflammation in LPS-stimulated macrophages through suppression of MAPK and NF-кB pathways. Sci. Rep. 2017, 7, 44252. [CrossRef] [PubMed]

26. Chen, X.; Yu, J.; Xue, C.; Wang, Y.; Tang, Q.; Mao, X. Mechanism of neoagarotetraose protects against intense exercise-induced liver injury based on molecular ecological network analysis. Biosci. Biotechnol. Biochem. 2019, 83, 1227-1238. [CrossRef]

27. Kim, M.; Lee, J.E.; Cho, H.; Jung, H.G.; Lee, W.; Seo, H.Y.; Lee, S.H.; Ahn, D.G.; Kim, S.J.; Yu, J.W.; et al. Antiviral efficacy of orally delivered neoagarohexaose, a nonconventional TLR4 agonist, against norovirus infection in mice. Biomaterials 2020, $263,120391$. [CrossRef]

28. Kwon, M.; Jang, W.Y.; Kim, G.M.; Kim, Y.H. Characterization and Application of a Recombinant Exolytic GH50A $\beta$-Agarase from Cellvibrio sp. KY-GH-1 for Enzymatic Production of Neoagarobiose from Agarose. ACS Omega 2020, 5, 29453-29464. [CrossRef] [PubMed] 